\title{
The Endocrine System at a Glance: Problemas y técnicas de traducción en el capítulo "Chemical Transmission"
}

\section{(The Endocrine System at a Glance: translation problems and techniques in Chapter "Chemical Transmission")}

\author{
ROSALÍA VILLA JIMÉNEZ \\ Z52vijir@uco.es \\ Universidad de Córdoba
}

Fecha de recepción: 14 de agosto de 2016

Fecha de aceptación: 30 de septiembre de 2016

Resumen: El discurso científico, en el que se enmarcan los textos médicos, persigue fines informativos, didácticos y comunicativos. Por ello, atiende a las siguientes particularidades: a) la veracidad, b) la precisión y c) la claridad (Navarro González, 2009). Sin embargo, persiste el uso de una sintaxis compleja, así como la utilización de elipsis, gerundios o incisos que pueden ser óbice para la comprensión del mensaje. En el presente trabajo se analizarán los principales problemas de traducción encontrados durante la actividad traductora del capítulo 2 del manual The Endocrine System at a Glance (2011), a los que se les dará solución mediante una determinada técnica de traducción (Hurtado Albir, 2011).

Palabras clave: Discurso científico, Lenguaje especializado, Problemas de traducción, Técnicas de traducción.

Abstract: Medical scientific discourse is said to be used for informative, didactic and communicative purposes. For this reason, it must be characterised by a) veracity, b) conciseness and c) clarity (Navarro González, 2009). However, in this type of discourse, it is not rare to find the use of a complex syntax, ellipsis, gerunds and/or bracketed phrases, which may be an obstacle for understanding the intended message of the text. The current paper analyses the main translation problems that have been come across during the translation process of Chapter 2 Chemical Transmission (The Endocrine System at a Glance, 2011). In order to solve these problems, the translation techniques proposed by Hurtado Albir (2011) have been required. 
Key words: Scientific discourse, Specialised language, Translation problems, Translation techniques.

1. TRADUCCIÓN EQUIFUNCIONAL: SITUACIÓN COMUNICATIVA, GÉNERO, TIPO Y REGISTRO TEXTUAL

Según el enfoque funcionalista de la traducción propuesto por Nord (1994), recogido en Hurtado Albir (1996), los principios por los que se rige la traducción funcional son los que se suceden a continuación.

En primera instancia, el objetivo de la traducción impone el método traslativo (principio de funcionalidad). En segundo término, los objetivos de la traducción aparecen limitados por la responsabilidad del traductor frente a los participantes en la interacción traductora (principio de lealtad). En tercer lugar, el objetivo de la traducción se determina por el encargo de traducción que expresa de manera explícita o implícita la situación comunicativa para la que el texto de llegada se necesita. En lo relativo a la situación comunicativa, insta decir que el parámetro más importante que la define lo constituye la función que debe cumplir el texto meta en la cultura de destino. En lo que al traductor se refiere, este debe procurar redactar el texto origen de manera que los receptores reconozcan la función pretendida en el texto de partida. Por último, la función del texto meta puede diferir con respecto a la del texto de partida, pero nunca puede ser incompatible con esta (Nord, 1996: 92).

En consecuencia, se distinguen dos tipos de traducción; por una parte, la traducción-documento y la traducción-instrumento, que es la que nos atañe. En esta se incluye la traducción equifuncional, la heterofuncional y la homóloga ${ }^{1}$. Conforme a esta taxonomía, el texto meta que se va a analizar obedece a la categoría de traducción equifuncional y, por ende, existirá una clara correspondencia entre las funciones comunicativas del texto meta y del texto de llegada.

Bajo un prisma funcionalista-textual, la traducción es un tipo de comunicación secundaria ${ }^{2}$. En esta, el traductor actúa como receptor del texto original y del mensaje del autor de la cultura de partida y como emisor del texto meta y del mensaje del autor de la cultura origen. ${ }^{3}$ Por otra parte,

\footnotetext{
${ }^{1}$ Consúltese Hurtado Albir, Amparo, La enseñanza de la traducción. Castelló: Publicacions de la Universitat Jaume I, 1996.

${ }^{2}$ Véase Hurtado Albir, A. Traducción y traductología. Madrid: Ediciones Cátedra, 2011. Esta implica la producción y la recepción del texto meta.

${ }^{3}$ Según Alcina Caudet (2005: 144), "por su naturaleza de mediador lingüístico el traductor debe ser capaz de reconocer, comprender y reproducir las estrategias comunicativas (géneros) que utilizan diferentes comunidades y grupos sociales para interactuar". Hurtado Albir (1996: 13) arguye que "[...] los mismos elementos que intervienen en un acto de comunicación directo, es decir, el emisor, el texto y el receptor. Sólo que incluye un factor más: el traductor. El traductor será así receptor del texto 1 y a la vez emisor del texto 2".
} 
este acto comunicativo y el doble papel asignado al traductor están determinados por la adecuación textual (la traducción) a una situación comunicativa, es decir, a los aspectos que afectan a las elecciones lingüísticas que los interlocutores realizan, como la naturaleza de la audiencia y el medio o el propósito de la comunicación. En esta situación comunicativa secundaria se realizan las categorías del registro (campo, tenor y modo), del género y del tipo de texto utilizado por el emisor (traductor) (García Izquierdo, 2011: 123) ${ }^{4}$.

La traducción que concierne en este trabajo muestra una situación comunicativa secundaria, que se encuadra en un contexto pedagógico y sanitario. Con la traducción del texto especializado se pretende cumplir una función de naturaleza fundamentalmente didáctica. Sin embargo, dado que la comunicación de conocimiento especializado implica un mayor esfuerzo cognitivo a cargo de los receptores de la lengua (español) y cultura meta (principalmente estudiantes del grado de medicina), el papel del traductor/emisor es efectuar una gradación media de especialización de la información textual transmitida para mantener la misma relación simétrica entre los expertos en endocrinología y los receptores de la lengua y cultura origen pretendida por los autores, Diana Wood y Ben Greenstein 5 .

La abstracción o especialización del texto científico abordado en el presente artículo, factor necesario para la adecuación textual, está condicionada por la situación comunicativa secundaria y por el contexto, que generan géneros textuales, tipos de textos y registros (Guantiva Acosta, 2008: 21). A tenor del concepto de género textual, este se define en términos de la capacidad de los hablantes de una lengua para reconocer un conjunto de características y funciones propias de algunos textos, que se correlacionan con situaciones sociales habituales en una cultura específica (López Rodríguez, 2000: 99-100). Alcina Caudet (2005: 144) elucida que el género textual entraña la relación entre los elementos del texto y del contexto [cultural] ${ }^{6}$. Por su parte, Swales (1990a: 58) explica el género textual destacando la función comunicativa, la organización o estructura, y las convenciones o prototipicidad del texto, que determinarán su género y

${ }^{4}$ Halliday y Hasan (1976: 21) definen el contexto de situación o situación comunicativa como "[a context] in which a text is embedded and it refers to all those extra-linguistic factors which have some bearing on the text itself".

5 La relación entre los interlocutores, experto-estudiante, es asimétrica, pero hay un acercamiento entre los participantes en la situación comunicativa al adaptar el nivel de abstracción del texto.

${ }^{6}$ Ezpeleta Piorno (2008: 430) resume que "los géneros sirven a un propósito comunicativo concreto, son reconocidos y utilizados por los miembros de una comunidad, se dan de manera recurrente, y son estructurados y convencionalizados. Por tanto, serían factores a tener en cuenta: los aspectos comunicativos, los aspectos sociales y culturales, los aspectos formales y los aspectos cognitivos". 
su aceptación en una determinada comunidad discursiva ${ }^{7}$.

Con esto, insta señalar que tanto el texto origen como el texto de llegada pertenecen al género semiespecializado textual manual o libro de texto, orientado principalmente a los estudiantes del grado de medicina (receptores de la cultura origen y meta) y, por ello, tiene la función de instruir de manera expositiva, y con un grado medio de especialización, adaptado al contexto situacional y al contexto cultural, pedagógico y sanitario en el que se enmarca. En efecto, los textos siguen una estructura muy clara para el contenido, con ilustraciones, figuras y tablas a comienzo del capítulo para introducir la temática, lo que ayuda al procesamiento cognitivo del conocimiento que se presenta, de modo que se reduce el nivel de abstracción y el esfuerzo por parte de los receptores en vías de especialización.

Por añadidura, el contenido textual está secuenciado de manera progresiva y lógica: un contexto a modo de introducción, seguido por el desarrollo del tema de interés, que culmina con una sección de preguntas y respuestas para afianzar el aprendizaje. Cabe apuntar que esta estructura convencional cumple la propiedad de adecuación textual, puesto que se ajusta al perfil del destinatario, al contexto didáctico y, por lo general, a la situación comunicativa.

En la estela funcionalista hallidayana, los registros textuales están definidos por la situación comunicativa secundaria y la función del texto, y están constituidos por tres elementos: 1) el campo (tema), que incluye la temática especializada. En cuanto al capítulo tratado en este trabajo, el campo se ha abarcado con un grado de abstracción medio, debido al marco comunicativo; 2) el tenor, que se refiere a la relación interpersonal entre los interlocutores, en la que se ha guardado semejante grado formal pero de especialización media; el propósito retórico del autor del texto original: expositivo en el texto de partida y de llegada; y la función comunicativa del texto: instruir al lector meta en formación, tal y como se expresa en el texto original; 3) el modo, que se refiere al canal de producción, transmisión y recepción del texto (Halliday, 1994: 49). En particular, la traducción completa del capítulo segundo del manual de endocrinología, de semejante manera que el original, se ha generado, transmitido y recibido en lengua escrita con material visual y descriptivo.

\footnotetext{
7 Con este ángulo, Alcina Caudet (2005: 144) expone que "el género textual integra (a) la dimensión convencional, es decir, aquellos elementos formales que corresponden a las expectativas de los lectores generadas por el contexto comunicativo y que guían los procesos de creación y comprensión del texto; (b) la dimensión comunicativa, es decir, el espacio de los participantes, las relaciones que entre ellos se establecen y las acciones que realizan; y (c) la dimensión cognitiva, o los modos que tienen las comunidades de entender, organizar y transformar la realidad que les es propia".
} 
Por último, en cuanto a la adscripción del texto origen a un tipo textual específico, cabe subrayar que puede considerarse como vehículo de expresión de un género textual. Hatim y Mason (1990: 1995) arguyen que los textos, en general, están condicionados por una serie de propósitos retóricos que permiten explicar la clasificación de un texto en un tipo determinado, que coinciden con la premisa de Halliday para el registro, por lo que se aprecia una estrecha relación entre los parámetros de registro y tipo de texto, delimitados por la situación comunicativa y el contexto o entorno físico-cognitivo de los interlocutores.

Según el propósito retórico del texto (argumentativo, expositivo y exhortativo), estos autores proponen los siguientes tipos textuales (Hatim y Mason, 1995: 198): a) textos argumentativos, en los que se expone una tesis para ser rebatida; $b$ ) textos expositivos, que tratan el análisis o síntesis de unos conceptos dados. Entre estos se encuentran la exposición pura o conceptual y la descripción-narración. En concreto, el texto origen (Chemical Transmission) y el texto meta obedecen a la categoría de los textos expositivos de exposición pura, ya que abordan fundamentalmente una temática concreta con objetividad, claridad y concisión. De forma análoga, proporciona a los futuros especialistas un instrumento de formación y referencia ${ }^{8}$ y c) textos exhortativos o instructivos, cuyo foco recae en la formación de conductas futuras.

\section{CARACTERÍSTICAS GENERALES DEL LENGUAJE CIENTíFICO}

Los lenguajes especializados de los ámbitos de la ciencia y la técnica conforman el lenguaje científico-técnico y poseen su propio mecanismo de transmisión lingüística, a pesar de que existan elementos comunes que los asocien. A tenor de la situación comunicativa y los participantes del acto de comunicación (emisor, receptor, contexto, función, canal y mensaje), podemos decir que el lenguaje científico se emplea con un mayor grado de especialización cuando la comunicación se produce entre especialistas, mientras que cuando se da entre profesionales y profanos se denomina lenguaje de divulgación, caracterizado por un menor grado de especialización.

En cuanto a las particularidades del discurso científico, en el que se enmarcan los textos médicos, Navarro González (2009: 90) resume las características principales de este discurso, con el que se persiguen fines informativos, didácticos y comunicativos a diferencia del lenguaje literario: a) la veracidad, b) la precisión y c) la claridad, por lo que el mensaje que se transmite en un texto científico (médico) debe presentar proposiciones

${ }^{8}$ Según Mayor Serrano (2007: 132) en su clasificación de los tipos de textos a partir de propósito de la transmisión de la información, el presente texto se encuadraría en los textos didáctico-referenciales. 
verdaderas y no dar lugar a la ambigüedad léxico-semántica mediante el uso de palabras o expresiones imprecisas". En consecuencia, "los errores verdaderamente graves del lenguaje médico serán, pues, aquellos que atenten contra alguno de estos tres rasgos".

Por su parte, Martín Martín et al. (1996) extienden la distinción de Navarro González y hablan de:

a) Universalidad: se plasma mediante la escasez de artículos, la abundancia de nombres comunes, la adjetivación específica, la prevalencia de verbos descriptivos, el predominio del presente para definir conceptos y el carácter enunciativo. De esta guisa, la universalidad se refleja a través de la nominalización terminológica.

b) Objetividad: el lenguaje utilizado ha de ser expositivo, dado que su función principal es la referencial o representativa, que hace referencia a los hechos de la realidad externa. Por ende, se pretende evitar la confusión y la ambigüedad.

c) Denotación: esta expresa el significado de las palabras, sin mezcla de nota cualitativa alguna, "estos lenguajes, que, por definición, son unívocos y objetivos, evitan las equivalencias laterales de valor estilístico y expresivo" (Martín Martín et al., 1996: 106-107).

d) Arbitrariedad: los términos no siempre se escogen según la convención del género científico (se usan metáforas, epónimos o referencias literarias y culturales).

e) Función del lenguaje: fundamentalmente es la referencial.

f) Formalización: depende del género textual, de modo que puede contar con un alto o bajo grado de formalización y univocidad del lenguaje.

g) Coherencia: es primordial para la comunicación del mensaje y para extraer conclusiones veraces.

h) Estructura y sintaxis del texto científico-técnico: abunda la sintaxis de párrafos cortos y correctamente conectados entre sí, ya que "brevity is a desirable quality in scientific writing, but accuracy and readability should have equal or higher status" (Stuart, 2007: 17).

En última instancia, Gutiérrez Rodilla $(1998 ; 2005)$ también establece las características del lenguaje científico, coincidiendo en numerosos aspectos con la propuesta de Martín Martín et al. (1996) y Navarro González (2009). Según esta autora, se destacan las siguientes propiedades:

${ }^{9}$ Balliu (2001: 33) resume las características del lenguaje médico en las siguientes: prevalencia de las relaciones denominativas monorreferenciales (a un término le corresponde un solo objeto y viceversa) y los escasos casos de redundancia. Asimismo, indica que en los textos médicos son poco frecuentes los medios lingüísticos subjetivos (imperativo, subjuntivo, signos de admiración, etc.) y los adornos verbales. 
a) Precisión: los términos no deben dar lugar a la ambigüedad. La precisión, sobre todo terminológica, deshace la posible ambigüedad del texto científico y, para ello, ha de poseer una definición fija, nítida y monosémica. La imprecisión aumenta cuanto mayor sea la sinonimia, la polisemia y la homonimia.

b) Neutralidad: hace alusión a las connotaciones subjetivas del emisor, propias del lenguaje y de los textos literarios. A su vez, esta suele asociarse con el uso de referencias bibliográficas, citas de autor, recursos visuales (tablas, diagramas, gráficos, etc.) para simplificar el discurso; con la impersonalidad, que se manifiesta fundamentalmente mediante procedimientos sintácticos, p. ej., el uso frecuente del plural de modestia (primera persona del plural); con la ausencia de segundas personas de singular y plural; con la utilización de verbos impersonales, de la voz pasiva o refleja y la sustitución de expresiones verbales por otras verbo-nominales.

c) Economía: el mensaje científico ha de ser conciso, por lo que entra en juego la sustitución de frases enteras por un único término. De igual modo, se pretende simplificar las estructuras sintácticas para no recargar el texto, "conviene evitar en el lenguaje médico el estilo retórico, no emplear párrafos largos, de complicada construcción y huir de las circunlocuciones" (Ordóñez Gallego, 1994: 36). Otros recursos son, por ejemplo, el uso de códigos matemáticos, químicos o informáticos para reforzar la información transmitida.

d) Función del lenguaje: predomina la función referencial o representativa, por medio de la que se aboga por la neutralidad. Sin embargo, también puede estar presente la función conativa, la metalingúïstica, sobre todo, en textos de carácter didáctico en los que se dilucidan conceptos, o la argumentativa (por ejemplo, un artículo médico). Esta combinación de funciones lingüísticas se explica, en su mayor parte, porque la actividad comunicativa y la interacción social están siempre latentes en una situación de comunicación.

e) Estabilidad: por lo general, la terminología científica suele resistir el paso del tiempo, pero es crucial revisarla, debido a los constantes avances en la rama de las ciencias, con el fin de evitar su desuso o que los términos sean obsoletos.

A pesar de los rasgos definitorios mencionados que deberían prevalecer en todo discurso científico-técnico, la realidad es otra bien distinta. Por ende, en el capítulo segundo del manual de endocrinología se observa que la precisión absoluta no obedece al prisma real de la comunicación, de manera que se da cabida a la imprecisión mediante la sinonimia, la polisemia, los neologismos y anglicismos. En segundo lugar, la objetividad o neutralidad de este tipo de lenguaje no siempre se cumple, puesto que la elección de los términos, verbos y adjetivos revela un 
determinado posicionamiento del autor. En tercera instancia, la economía del lenguaje se franquea con el uso de una sintaxis compleja de subordinación, así como con la tendencia a emplear enumeraciones, gerundios o incisos que pueden ser óbice para la comprensión del mensaje. En último término, el texto meta no está exento de la convivencia entre la función metalingüística y la función principal, la referencial.

\section{CRITERIOS DE TRADUCCIÓN}

La traducción equifuncional del capítulo segundo de The Endocrine System at a Glance (2011) presenta, con un papel dominante, las técnicas de traducción modulación, supresión y transposición. Es necesario poner de relieve que en una oración o en un párrafo coexiste más de una técnica con el objeto de conseguir la naturalización de la traducción en la lengua meta.

Algunos autores como Navarro González (2009), Martín Martín et al. (1996) y Gutiérrez Rodilla (1998; 2005), entre otros, comparten la premisa de que las características principales del discurso médico, con el que se persiguen fines informativos, didácticos y comunicativos a diferencia del lenguaje literario, se resumen en: a) veracidad, b) precisión y c) claridad. Por tanto, el propósito principal es que el mensaje de un texto científico presente proposiciones verdaderas sin dar lugar a la ambigüedad léxicosemántica, textual o pragmática. A pesar de estos rasgos, la realidad es otra bien distinta, puesto que se observa que la precisión absoluta no obedece al prisma real de la comunicación, de manera que se da cabida a la imprecisión en los diferentes niveles del discurso médico.

En consonancia con el modelo propuesto por Hurtado Albir (2011) y el grupo PACTE ${ }^{10}$, se ha establecido la taxonomía de los siguientes problemas de traducción de la siguiente manera: a) el plano morfosintáctico (orden de las palabras, uso del gerundio, adverbios terminados en -ly, omisión del artículo definido, uso de la voz pasiva pronominal e impersonal de la oración, preposiciones); y $b$ ) problemas textuales, entre los que se encuentran los mecanismo de cohesión (la referencia, repetición, sinonimia). El conjunto de problemas encontrados da fe de que los objetivos del lenguaje y del texto médico son alcanzables en cierto modo y que, los textos origen y meta estudiados adolecen de muchas características que definen este tipo de discurso, por lo que son un ejemplo más de la ambigüedad y la imprecisión.

10 El denominado grupo PACTE (Proceso de Adquisición de la Competencia Traductora y Evaluación), encabezado por Hurtado desde 1997 ha llevado a cabo una serie de investigaciones que han arrojado una tipología y descripción de las subcompetencias traductoras (Umaña Corrales y Suárez de la Torre, 2011: 20). 


\subsection{Problemas de traducción y solución de problemas del capítulo 2. Transmisión química ${ }^{11}$ \\ Los problemas de traducción que se presentan a continuación muestran que los principios básicos con los que se define al discurso médico son, en muchas ocasiones, utópicos, puesto que no se cumplen en su totalidad.}

3.1.1. Problemas en el plano morfosintáctico: técnicas de traducción para la resolución de problemas ${ }^{12}$

Lorenzo Criado (1996: 631) denomina "anglicismos de frecuencia" a un empleo bastante recurrente de la voz pasiva, de ciertos verbos modales y de los adverbios terminados en -ly (-mente) en la lengua inglesa en comparación con el español. En especial, el autor hace alusión al uso inmoderado de determinadas expresiones o palabras que excluyen otras opciones existentes en el español, que confieren variedad y modulación al mensaje. En consonancia con esta definición, Rodríguez Medina (2002: 151) indica que el efecto de estos "anglicismos de frecuencia" es un aumento de construcciones que existen en la sintaxis española por influjo del inglés.

\subsubsection{Orden de las palabras}

El orden de las palabras entraña el orden de los elementos que constituyen la estructura de la oración, así como la posición que ocupan determinados complementos y modificadores con respecto a los principales, como los adverbios-verbos o los adjetivos-sustantivos (García González, 1997-1998: 599). Es bien sabido que la estructura básica de la oración en inglés es sujeto + verbo + objeto $(\mathrm{CD}, \mathrm{Cl})$ + complementos; normalmente un orden que responde a una secuencia lógica y rígida, aunque no es extraño

\footnotetext{
${ }^{11}$ El capítulo segundo del manual The Endocrine System de la serie At a Glance se ocupa de la comunicación celular e intracelular. Este proceso se lleva a cabo a través de mecanismos de transmisión química, en esencia, a) la comunicación hormonal o endocrina, en la que se despliegan las hormonas con función paracrina, autocrina, endocrina, neuroendocrina, neural y feromonal, y b) la neurotransmisión, en la que se destaca la acción de los neurotransmisores y los neuromoduladores, encargados de transmitir información de una neurona a una célula receptora. De igual manera, los mecanismos de transporte a través de la membrana celular, que se deslindan en difusión simple, difusión facilitada, transporte activo, canales iónicos, ósmosis, endocitosis (fagocitosis, pinocitosis) y exocitosis, y el transporte hormonal a través de la sangre, participan en la comunicación celular.

12 Las técnicas de traducción utilizadas para solucionar los problemas de traducción encontrados en el texto origen/meta se engloban en la clasificación propuesta por Hurtado Albir (2011: 256-271).
} 
encontrar esta estructura con alteraciones con el fin de dar énfasis a ciertos elementos.

De igual manera, la sintaxis española sigue este orden lógico básico, pero predomina una mayor libertad constructiva y la facilidad con que se puede invertir los elementos de la oración (Martín Vivaldi, 1995: 88). Vázquez Ayora (1997: 407) también subraya la linealidad del inglés con la construcción "envolvente" del español, en parte gracias a su sistema complejo de desinencias verbales.

a.1.) The neurotransmitters are inactivated by enzymes or taken up into the nerve that released them and metabolized.

b.1) Los neurotransmisores son inactivados por las enzimas o recaptados por la neurona que los liberó y metabolizados.

La oración subordinada pasiva en las dos versiones implica cierto grado de dificultad para la comprensión del mensaje y la formulación de la estructura sintáctica en la lengua española. Primero, se detecta dos sujetos pacientes con sus respectivos verbos (inactivated by enzymes or taken up into the nerve > inactivados por las enzimas o recaptados por la neurona); luego, el segundo sujeto paciente entraña una subordinada de relativo, que como bien es sabido, ha de seguir inmediatamente a su antecedente; por último, el verbo en participio -ed ("metabolizados") concluye la oración. Este verbo obedece a la pasiva primera (are inactivated > son inactivados) y su desplazamiento al término de la oración es óbice para la maximización del mensaje. En el caso de ocupar el puesto del primer verbo, el valor de consecuencia de las dos acciones anteriores no se cumpliría. En consecuencia, es preferible mantener la literalidad con respecto a la versión a.1).

a.2) If two solutions containing the same chemical, one concentrated and the other relatively dilute, are separated by a membrane which is completely permeable and passive, the concentrations of the chemical on either side of the membrane will eventually end up being the same through simple diffusion of solutes.

b.2) En el caso de que una membrana completamente permeable y pasiva separe dos soluciones con la misma sustancia química, una concentrada y la otra relativamente diluida, las concentraciones químicas a ambos lados de la membrana, a la larga, se igualarán debido a la difusión simple de los solutos.

Técnica aplicada: Modulación estructural y enfoque. La modificación de enfoque (voz pasiva del original > voz activa en la traducción) conlleva la 
reorganización de la estructura sintáctica de la oración subordinada adverbial con valor hipotético en el texto origen.

a.3) Receptor-mediated endocytosis is the ingestion of specifically recognized substances by coated pits.

b.3) La endocitosis mediada por receptores se caracteriza por la ingestión de sustancias reconocidas específicamente por invaginaciones recubiertas.

Con respecto al uso del guión en la adjetivación inglesa para unir dos calificativos, en particular al sustantivo endocytosis > endocitosis, cabe decir que en español correspondería utilizar una conjunción o una preposición.

\subsubsection{Uso del gerundio}

El gerundio suele emplearse en contextos en los que se debe utilizar construcciones no verbales, "el gerundio español funciona en la oración como modificador verbal, aunque con restricciones que limitan su aparición en el discurso. No ocurre lo mismo en inglés, donde la forma en -ing dispone de una variedad de usos y matices" (Rodríguez Medina, 2002: 153). El abuso del gerundio en la lengua española es reflejo de la influencia de la lengua anglosajona que, en muchas ocasiones, origina usos impropios como el gerundio de posterioridad (o consecuencia), el gerundio con valor de adjetivo especificativo o la perífrasis de acción durativa (Smith, 1997: $26)^{13}$.

De forma semejante, Amador Domínguez (2007: 121-122) expone otros casos en los que el uso del gerundio en español es incorrecto ${ }^{14}$ :

-El gerundio en -ing con valor de modificador suele traducirse al español como un gerundio en lugar de una subordinada adjetiva que modifica al antecedente de la oración principal.

-El gerundio en -ing a comienzos de la oración, así como los infinitivos, debe evitarse y sustituirse por una oración que exprese el mismo significado de la forma inglesa. Asimismo, es preferible aplicar esta norma a los títulos.

\footnotetext{
${ }^{13}$ Véase Fundéu BBVA para una aclaración del gerundio de posterioridad y simultaneidad. Disponible en línea en: http://www.fundeu.es/recomendacion/el-gerundio-con-valor-deposterioridad-es-incorrecto-825/. [Fecha de consulta: 30 de agosto de 2016].

${ }_{14}$ Navarro González (2008: 219-220) pone de relieve el uso impropio del gerundio copulativo o ilativo en los textos médicos, que abunda sobre todo en la forma "siendo" o en la terminación iendo, con valor incorrecto de consecuencia o posterioridad, p. ej.. "La afectación diastólica en la acromegalia es muy frecuente, apareciendo prácticamente en la totalidad de los pacientes con enfermedad evolucionada, y siendo probablemente secundaria a los cambios histológicos que se producen en el corazón de estos pacientes".
} 
García González (1997-1998: 608), por su parte, propone los siguientes ejemplos para el uso aceptado del gerundio:

-El gerundio depende de un verbo de percepción y resalta el aspecto durativo de la acción, p. ej.: I have seen children suffering (He visto a niños sufriendo/que sufren)

-El gerundio funciona como núcleo verbal de una subordinada adverbial, p.ej.: Seeking ways to support themselves and their families, they move north from the highlands (Buscando/en busca de/para buscar sustento para ellos mismos y sus familias, emigran hacia el norte desde el altiplano).

No obstante, el autor enfatiza que cuando el gerundio en -ing tiene una función que complementa a un sustantivo, la lengua española rechaza su traducción por gerundio. Es preferible, en estas ocasiones, emplear una subordinada de relativo.

a.1) Autocrine: acting on the cells that synthesized them.

b.1) Autocrina: actúa sobre las células que la sintetizan.

Técnica aplicada: Modulación léxica. Este procedimiento se ha llevado a cabo al convertir una forma no personal (acting) a una forma personal (presente de indicativo) en español en la versión traducida b.1). El signo tipográfico de los dos puntos (:) desempeña una función conectora entre el sujeto (autocrine/autocrina) y el resto de la oración; a saber, se pueden reemplazar por el nexo "que", lo que indica una subordinada adjetiva que se refiere a las hormonas endocrinas mencionadas en el párrafo anterior, Homones are chemical messengers ("Las hormonas actúan como mensajeros químicos").

a.2) An example is insulin, secreted by pancreatic $b$ cells and affecting secretion of glucagon by pancreatic a cells.

b.2) Por ejemplo, la insulina, secretada por las células $\beta$ pancreáticas, influye en la secreción de glucagón por las células $\alpha_{2}$-pancreáticas.

Técnica aplicada: Modulación léxica y de enfoque. Primero, en la versión traducida b.2) se ha empleado un presente de indicativo por el gerundio del texto origen. La forma no personal del verbo to affect (affecting) tiene valor de modificador con respecto al antecedente insulin (sujeto), Insulin is an example. Esta función modificadora en -ing debería expresarse en español con una subordinada adjetiva, "que influye". Segundo, la modulación abarca también al resto de los elementos de la oración. Así, la oración copulativa en inglés, seguida de la doble subordinada relativa, se transforma en una oración principal con una subordinada, "secretada por las 
células $\beta$ pancreáticas". Este procedimiento minimiza el esfuerzo cognitivo y maximiza la transmisión del mensaje.

a.3) If two solutions containing the same chemical, one concentrated and the other relatively dilute, are separated by a membrane [...].

b.3) En el caso de que una membrana completamente permeable y pasiva separe dos soluciones con la misma sustancia química, una concentrada y la otra relativamente diluida [...].

Técnica aplicada: Supresión lingüística. El gerundio en inglés containing debería traducirse por una oración subordinada adjetiva con función modificadora del antecedente, "que contiene". Sin embargo, se ha optado por la supresión lingüística del sintagma adjetival por un sintagma preposicional en la versión traducida b.3), "con la misma sustancia química". Este procedimiento no es óbice para la transmisión completa del mensaje, puesto que no resta relevancia ni tampoco reduce la carga conceptual de la oración. Por el contrario, modera la posible imprecisión y ambigüedad que pudiera desprenderse de esta oración compleja.

\subsubsection{Adverbios terminados en -ly (-mente)}

En lo que a los adverbios acabados en -ly (-mente) se refiere, su uso no es agramatical en la lengua término (español), pero la aparición excesiva a lo largo del texto meta frente a otras opciones más características y habituales en la lengua española restringe otras posibilidades más naturales. En esta vertiente, García González (1997-1998: 615) menciona que la utilización del sufijo -mente en español "se trata de un proceso de derivación correcto desde el punto de vista gramatical, y a veces estas formaciones contribuyen a dar un matiz de solemnidad al discurso. Sin embargo, la proliferación de estos adverbios largos puede crear un tono monótono".

Con la misma opinión se pronuncia Amador Domínguez (2007: 121), que afirma que se debe recurrir a otras categorías de palabras o frases que equivalgan en significado a los adverbios terminados en -ly en inglés. De esta manera, se evitará caer en las repeticiones que resultan monótonas y cacofónicas. En última instancia, Rodríguez Medina (2002: 153) explicita que el uso reiterado de los adverbios en -mente va en contra de la naturalidad del español, que se sirve de otras estructuras (p. ej., de forma/ manera + adjetivo $)^{15}$.

${ }^{15}$ López Guix y Minett Wilkinson (1997: 119) arguyen que "en castellano, la derivación en mente [...] es también posible"-y perfectamente correcta-, pero su utilización es mucho más moderada que en inglés". 
Ejemplos de adverbios terminados en -ly (-mente): TO > TM

Eventually > A la larga, finalmente, con el tiempo.

Physiologically active > Actividad biológica*.

Usually > Por lo general, en general, por norma, normalmente, generalmente.

Relatively > En parte, relativamente.

a.1) [...] the free fraction of the hormone is physiologically active and available to the tissues and for metabolism.

b.1) [...] la fracción de hormona libre posee actividad biológica y está disponible para uso por los tejidos y el metabolismo.

*Técnica aplicada: Modulación de la estructura. El adverbio en -ly se ha modificado en un sintagma verbal de CD. De este modo, se altera la forma del texto meta con respecto al texto origen, pero se mantiene la fidelidad en el trasvase del mensaje del original.

a.2) This is because there are many molecules of the chemical on the concentrated side, and therefore a statistically greater probability of movement [...].

b.2) Esto se debe a que hay muchas moléculas en el lado concentrado y, por ende, una mayor probabilidad estadística de transporte $[\ldots]$.

Técnica aplicada: Transposición. El adverbio que termina en -ly en inglés cambia de categoría gramatical (adverbio > sintagma nominal de CD), pero se mantiene el mismo concepto.

\subsubsection{Omisión del artículo definido (the $>$ el/la/los/las)}

Greenbaum y Quirk (1990: 72 y ss.) señalan que el artículo definido o central determiner (the) suele suprimirse $(\varnothing)$ cuando el referente tiene valor genérico. En español, por el contrario, el artículo determinado es imprescindible y siempre precede al término genérico y a la referencia específica ${ }^{16}$.

a.1) (Ø) Hormones are chemical messengers.

b.1) Las hormonas actúan como mensajeros químicos.

${ }^{16}$ Véase Montero, Sonia, "El artículo y otros fantasmas del nombre". En: redELE, 21, 2011, pp. 1-28. 
a.2) [...] for example insulin-like growth factor (IGF-1) which stimulates cell division which produced it.

b.2) [...] Por ejemplo, el factor de crecimiento insulinoide 1 (IGF-1) activa la división de la célula que lo produce.

Por otra parte, como propone la Fundéu BBVA, "En principio todas las siglas deben ir precedidas por el artículo correspondiente: femenino si el sustantivo principal es femenino, y masculino cuando ese sustantivo es masculino"17.

a.1) Diagnosis of $\mathrm{GH}$ deficiency.

b.1) Diagnóstico de insuficiencia de $\mathrm{GH}$.

a.2) $\mathrm{GH}$ fails to suppress normally in acromegaly [...].

b.2) Normalmente, la GH no se inhibe en la acromegalia [...].

En esta serie de ejemplos, el sintagma preposicional actúa como CD en el primer caso, mientras que, en el segundo, la sigla asume un valor de sujeto, por lo que el artículo es necesario.

\subsubsection{Uso de la voz pasiva pronominal e impersonal de la oración}

Navarro González et al. (1994: 461) señalan que el español tiende a evitar la voz pasiva, por lo que, aunque su uso no sea incorrecto y a veces sea imprescindible, "[la pasiva es] más propia del inglés [...] y su abuso es una de las cosas que más desfiguran el genio de nuestra lengua y qué más da a un escrito aire forastero". Además, presenta una marcada preferencia por la construcción activa ${ }^{18}$. Este argumento concierta con el de Joaquín Segura (2001: 55), puesto que afirma que la repetición de la voz pasiva (verbo ser + participio) en las traducciones del inglés técnicas y médicas se contraponen, hasta cierto punto, a la costumbre del español. García González (1997-1998: 610) aclara que esta construcción sintáctica puede resultar ambigua en español.

Por lo general, se suele preferir la construcción activa con sujeto pronominal a la activa impersonal con el verbo en tercera persona del plural,

17 Disponible en línea en: http://www.fundeu.es/consulta/siglas-y-articulo-1052/. [Fecha de consulta: 29 de agosto de 2016]. Para más información sobre las siglas, sus usos y la formación de su plural consúltese Real Academia Española. Diccionario de la Lengua Española (22. ${ }^{\mathrm{a}} \mathrm{ed}$.). 2001.

${ }^{18}$ En palabras de Navarro González et al. (1994: 463), el uso de la voz activa en primera persona singular es anecdótico y "puede deberse en parte a la tendencia a la autoría múltiple en los artículos médicos [...] el motivo fundamental es sin duda el miedo del médico a parecer inmodesto [...] se prefiere la voz activa con el plural de modestia en lugar de considero que [en el caso de no recurrir a la voz pasiva]". La costumbre tan arraigada del plural de modestia puede llevar a la ambigüedad.

Hikma 15 (2016), 117-141 
a la activa impersonal con se y a la pasiva pronominal o refleja. No obstante, se tiende a recurrir a la pasiva cuando "no sabemos o queremos callar quién es el agente de una determinada acción, o cuando la utilizamos como recurso estilístico o para evitar repeticiones dentro de una misma oración", como subraya Joaquín Segura (2001: 55). En esta vertiente, Amador Domínguez (2007: 123) indica que la construcción de la voz pasiva con los verbos ser o estar (to be) no es muy frecuente y, como consecuencia de ello, se favorece el uso de la pasiva pronominal con la partícula $s e^{19}$.

En cuanto a la voz pasiva pronominal o refleja, apuntan estos autores, la partícula se desempeña un papel como indicador del sentido pasivo de la oración y no actúa como un elemento reflexivo. A medida que el tiempo avanza, los ejemplos de pasiva pronominal han preñado la lengua española, de forma que esta voz pasiva es la forma más frecuente, tanto en la lengua escrita como hablada.

En este tipo de pasiva, el sustantivo que acompaña al verbo tiene la función de sujeto; por ende, el verbo ha de concertar en número con este sustantivo. Asimismo, insta subrayar que la pasiva nominal no admite complemento agente, para la que se emplearía la voz pasiva perifrástica. Otra característica distintiva de la construcción pasiva pronominal es que únicamente se expresa en tercera persona (singular o plural) y solo se refiere a cosas o acciones, de lo contrario, se obtendría una pasiva refleja que daría lugar a la ambigüedad. En estos casos de confusión, es aconsejable utilizar una pasiva perifrástica.

a.1) These chemicals are termed neurotransmitters.

b.1) Estas sustancias se denominan neurotransmisores.

En la versión traducida b.1), la construcción de pasiva pronominal con se acompaña al sustantivo, ya que este es el sujeto de la oración. Por tanto, la voz pasiva debe concordar en número con este elemento.

a.2) [...] this is neurotransmission, when a chemical is released by one neurone and acts on an adjacent neurone (Fig. 2b).

b.2) [...] participa en la neurotransmisión, es decir, una neurona libera una sustancia química que actúa sobre la neurona adyacente (fig. 2b).

19 Véase, asimismo, García, José Enrique, "Anglicismos morfosintácticos en la traducción periodística (inglés-español): análisis y clasificación". En: CAUCE Revista de Filología y su Didáctica, 20-21, 1997-1998, pp. 593-622. 
Técnica aplicada: Modulación de enfoque. En la traducción b.2) se observa una modificación de la voz de la oración (voz pasiva del original > voz activa del texto meta).

a.3) [...] Therefore chemicals can be transported across the membrane against a concentration gradient [...]

b.3) [...] de manera que las sustancias químicas se pueden transportar a través de la membrana contra un gradiente de concentración $[\ldots]$.

En lugar de emplear la construcción pasiva (ser + participio), "pueden ser transportadas", se ha preferido la pasiva pronominal con se. De igual modo, la perífrasis verbal de posibilidad (poder + verbo) introducida por esta partícula concierta en número con el sujeto nominal, "las sustancias químicas".

a.4) $[\ldots]$ and the transport process can be interrupted by metabolic poisons.

b.4) [...] las toxinas metabólicas interrumpen este transporte.

Técnica aplicada: Modulación de enfoque. Se ha optado por la voz activa en la versión traducida b.4) para la estructura perifrástica (can + be + -ed) en la versión original a.4), más natural en la lengua española. Este giro, por añadidura, resalta el elemento oracional agente que realiza la acción de interrumpir el desplazamiento de las sustancias químicas en el transporte activo.

\subsubsection{Preposiciones}

En relación con las preposiciones, insta decir que el uso de una preposición u otra está determinado por el carácter idiomático. Lorenzo Criado (1996: 617-618) pone de manifiesto que en muchas ocasiones se ha exagerado el influjo del inglés en el uso de las preposiciones con respecto a las propias del español, de forma que "resulta imprudente desautorizar ciertas construcciones por su coincidencia con las inglesas, sin pensar que las posibilidades del español todavía están claramente faltas de inventario y codificación". Los ejemplos seleccionados muestran aquellas preposiciones posiblemente calcadas de la estructura inglesa y las que se emplearían normalmente en español en el mismo contexto. Asimismo, estos se dividen según las distintas funciones sintácticas que desempeñan: 
-Suplemento o complemento de régimen

a.1.) Cells will shrink or swell depending on the concentrations of the solutes on either side of the membrane.

b.1) Las células se encogen o distienden según la concentración de solutos a cada lado de la membrana.

El complemento de régimen de la versión a.1) se traduciría literalmente como "dependiendo sobre/dependiendo en" en lugar de "depender de". En este caso, se ha optado por la preposición "según" para evitar el uso incorrecto del gerundio en español.

\section{-Complemento circunstancial}

a.2) [...] they are carried in the bloodstream or through another aquous ducting system, such as lymph.

b.2) [...] órganos a los que se transporta a través del torrente sanguíneo u otro sistema ductal, como el linfático.

En este ejemplo, además, se observa la supresión de la preposición through de la versión a.2), ya que se infiere que la preposición in tiene el mismo sentido que "a través". Las hormonas endocrinas pasan de un lado a otro por medio del torrente sanguíneo, que actúa como recipiente en el que se desplazan estas hormonas.

a.3) [...] For example insulin-like growth factor (IGH-1) which stimulates cell division in the cell which produced it.

b.3) [...] Por ejemplo, el factor de crecimiento insulinoide 1 (IGH-1) activa la división de la célula que lo produce.

El sintagma preposicional de la versión a.3) expresa el lugar en el que se realiza la acción verbal, es decir, el proceso de división se genera en la célula que estimula el factor de crecimiento insulinoide 1 (IGH-1). El sintagma preposicional de la versión traducida b.3) denota lugar igualmente.

a.4) Many hormones are secreted in a pulsatile fashion [...].

b.4) Muchas hormonas se secretan de forma pulsátil [...].

El sintagma preposicional de la versión original a.4) implica el modo en el que se ejecuta la acción verbal. Para expresar este sentido, en español se cuenta con el sintagma preposicional con valor circunstancial "de forma, de manera o de modo" y no "en forma [de]". 
a.5) Paracrine: acting on cells or neighbouring cells.

b.5) Pacracrina: actúa sobre las células vecinas.

Joaquín Segura (2001: 55) ilustra con otro ejemplo la intrusión de este galicismo en la lengua española, "Se han producido cambios funcionales sobre el patrón normal". La preposición "sobre" en la versión traducida b.5) debe sustituirse por "en".

\subsubsection{Problemas textuales}

\subsubsection{Cohesión}

Los problemas de traducción también se extrapolan al nivel textual, es decir, a la organización de un texto mediante la cohesión. Baker (2001: 180) define la cohesión como una red de relaciones léxicas y gramaticales que vinculan las distintas partes que conforman el texto, "cohesion is a surface relation; it connects together the actual words and expressions that we can see or hear". La autora fundamenta su modelo de cohesión en la propuesta de Halliday y Hasan (1976), de modo que se distinguen cinco mecanismos de cohesión: a) la referencia, b) la sustitución, c) la elipsis, $d$ ) la conjunción y e) la cohesión léxica. A continuación, se explican los procedimientos que se han utilizado y se ofrece un ejemplo ilustrativo extraído de la traducción.

\section{a) La referencia}

a.1) Hormones are chemical messengers. They may be classified several ways (Fig. 2a).

b.1) Las hormonas actúan como mensajeros químicos y se clasifican de varias maneras según el tipo de transmisión química (fig. 2a).

Técnica aplicada: En la versión inglesa a.1), el pronombre personal they se refiere al sujeto de la oración anterior, hormones, por lo que colegimos que desempeña una función anafórica. En la traducción b.1), este pronombre deíctico está implícito en la construcción pasiva pronominal, "se clasifican". De igual forma, se advierte la utilización de la técnica de traducción de la amplificación, "según el tipo de transmisión química", por la que introducimos una precisión que no aparece formulada en el original.

a.2)These chemicals are termed neurotransmitters. Neurotransmitters produce virtually instantaneous effects $[\ldots]$. 
b.2) Estas sustancias se denominan neurotransmisores y su efecto es prácticamente inmediato [...].

Técnica aplicada: La versión original a.2) es un claro ejemplo de referencia semántica, es decir, de repetición de un término, de modo que se establece una relación directa entre dos expresiones lingüísticas. Por el contrario, en la versión traducida b.2) se ha evitado el uso de la repetición, más propia de la lengua inglesa, y se ha sustituido el nombre "neurotransmisores" por un pronombre que indica posesión, "su". La referencia anafórica se consigue, además, mediante la modulación de enfoque de la oración de la versión en inglés (oración coordinada > oración copulativa).

En semántica, la referencia hace alusión a la relación directa entre una palabra y el objeto de la realidad. Sin embargo, en el modelo de Halliday y Hasan, la referencia denota la relación entre dos expresiones lingüísticas. Esta herramienta de cohesión facilita la recuperación de la información que el emisor ha transmitido por medio de otra expresión lingüística inmediata. Aún más, el artículo determinado (the > el/la/los/las), los pronombres personales y los pronombres demostrativos se convierten en las unidades de referencia más usuales en la lengua, que pueden actuar como deícticos anafóricos o catafóricos. De forma análoga, estos autores señalan otros procedimientos de cohesión que se utilizan con el propósito de proporcionar información mencionada con anterioridad.

\section{b) Repetición}

a.1) Facilitated transport is the transport of chemicals across membranes by carrier proteins.

b.1) La difusión facilitada consiste en que las proteínas transportadoras conducen sustancias químicas a través de las membranas.

La versión a.1) presenta la repetición del término transport que vincula de forma inmediata la información, mientras que la versión b.1) prescinde de este elemento de referencia semántica y recurre a una oración sustantiva de complemento de régimen.

c) Sinonimia

La sinonimia es un fenómeno muy frecuente en los ámbitos especializados en todas las lenguas, "siendo el dominio biosanitario uno de los más prolíficos" (Jiménez Gutiérrez, 2009: 580). Este mecanismo origina la ruptura de la precisión y la univocidad en los textos médicos mediante la posibilidad de recurrir a varios términos que se refieren a un único concepto, 
o como explicita Alcaraz Ariza (2002: 65) "[la sinonimia es] un proceso mediante el cual un referente adquiere varios nombres no relacionados históricamente"20.

Gutiérrez Rodilla (1998) dilucida las razones a las que se debe la sinonimia terminológica, entre las que se encuentran: a) la creación de nuevos términos sinónimos con base en los formantes griegos y latinos (emétic/vomitivo, absceso infralinguall absceso sublingual)) y b) la formación de sinónimos o introducción de unidades léxicas de origen sajón por el influjo de la lengua inglesa, lingua franca del discurso científicotécnico en la actualidad, que sustituyen a la denominación en la lengua española. Alcaraz Ariza (2002) añade que la existencia de niveles de lengua, como el culto y el popular, dan origen a la formación de sinónimos (epitelioma/carcicoma cutáneo/ cáncer de piel).

Por su parte, Jiménez Gutiérrez (2009: 580) señala que la sinonimia también depende de la preferencia de las comunidades científicas y escuelas por la utilización de diferentes términos para designar conceptos idénticos e incluso, "el prestigio del inglés como lengua de comunicación [...] hace que muchos investigadores prefieran utilizar los términos anglosajones frente a los términos propios de su comunidad científica". De forma análoga, en otros casos, existe la convivencia entre términos cultos y términos más próximos a la lengua común ${ }^{21}$.

a.1) Facilitated transport is the transport of chemicals across membranes by carrier proteins. The process does not require energy and cannot, therefore, transport chemicals against a concentration gradient.

b.1) La difusión facilitada consiste en que las proteínas transportadoras conducen sustancias químicas a través de las membranas. Este proceso no necesita aporte de energía, por lo que las sustancias no se pueden transportar contra un gradiente de concentración.

En la versión original a.1) y en la traducida b.1), el término process ("proceso") tiene un valor sinonímico que hace alusión anafórica a este tipo transporte de sustancias químicas.

\section{CONCLUSIONES}

La traducción que se ha abordado en el presente estudio se define como una situación de comunicación secundaria que se encuadra en un

${ }^{20}$ Para tener información más detallada sobre las denominaciones sinonímicas, véase Alcaraz, Ma Ángeles, "Los epónimos en medicina". En: Ibérica, 4, 2002, pp. 55-73.

${ }^{21}$ Jiménez Gutiérrez (2009) recoge la taxonomía de Urrutia Cavero (2005), "Análisis cualitativo de la traducción científica y técnica: los errores semánticos y su clasificación", de los términos sinónimos: "sinónimos absolutos", "sinónimos casi absolutos" y "sinónimos falsos". 
contexto pedagógico y sanitario. Con la traducción de este texto especializado se pretende cumplir una función de naturaleza fundamentalmente didáctica. Dado que la comunicación de conocimiento especializado implica un mayor esfuerzo cognitivo a cargo de los receptores de la lengua (español) y cultura meta, como emisores de las particularidades del texto original en el texto meta debemos admitir una gradación media de especialización de la información textual transmitida para mantener la relación simétrica que ya existe entre los expertos en endocrinología (emisores, autores, Diana Wood y Ben Greenstein) y los destinatarios de la cultura origen.

En relación a la definición y tipología de problemas de traducción, Hurtado Albir (2011) define los problemas de traducción como las dificultades lingüísticas y extralingüísticas de carácter objetivo que encuentra el traductor. Con base en esta aproximación, Hurtado Albir propone cinco categorías de problemas de traducción que, a su vez, han sido empleadas por el grupo PACTE en su investigación sobre la competencia traductora y su adquisición: a) problemas lingüísticos (plano léxico y morfosintáctico); b) problemas textuales (coherencia y cohesión, progresión temática, tipología textual y estilo); c) problemas extralingüísticos (cuestiones temáticas, enciclopédicas y culturales); d) problemas de intencionalidad (intención, intertexualidad, actos de habla y presuposiciones e implicaturas) y e) problemas pragmáticos (características del destinatario y del contexto de traducción).

En consonancia con Hurtado Albir y el grupo PACTE, se ha establecido la taxonomía de los siguientes problemas de traducción: a) problemas en el plano morfosintáctico (orden de las palabras, uso del gerundio, adverbios terminados en -ly, omisión del artículo definido, uso de la voz pasiva pronominal e impersonal de la oración y preposiciones); y $b$ ) problemas textuales, entre los que se encuentran los mecanismos de cohesión (referencia y conectores lógicos). El resto de problemas propuestos en el modelo de PACTE y Hurtado Albir se han omitido porque realmente los obstáculos encontrados durante la traducción del texto fuente no han sido óbice para proseguir con la actividad traductora.

REFERENCIAS BIBLIOGRÁFICAS

ALCARAZ, Ma Ángeles, "Los epónimos en medicina". En: Ibérica, 4, 2002, pp. 55-73.

ALCINA, Amparo, "La implementación del concepto de género textual en los corpus electrónicos para traductores". En: El género textual y la traducción: reflexiones teóricas y aplicaciones pedagógicas. I. García Izquierdo (ed.). Bern: Peter Lang, 2005, pp. 93-117.

AMADOR, Nidia, "Diez errores usuales en la traducción de artículos 
científicos". En: Panace@: Revista de Medicina, Lenguaje y Traducción, 8.26, 2007, pp. 121-123.

BALLIU, Christian, "El peligro de la terminología en traducción médica". En: Panace@: Revista de Medicina, Lenguaje y Traducción, 2.4, 2001, pp. 30-39.

EZPELETA, Pilar, "El informe técnico. Estudio y definición del género textual". En: en Actas del III Congreso Internacional de la Asociación Ibérica de Estudios de Traducción e Interpretación. La traducción del futuro: mediación lingüística y cultural en el siglo XXI. Barcelona 22-24 de marzo de 2007. L. Pegenaute, J. DeCesaris, M. Tricás y E. Bernal. Barcelona (eds.) PPU, 2008, pp. 429-438.

GARCíA, Isabel, "Vertiente comunicativa del género". En: Competencia textual para la traducción. I. García Izquierdo (ed.). Valencia: Tirant Lo Blanch, 2011, pp. 122-146.

GarcíA, José Enrique, "Anglicismos morfosintácticos en la traducción periodística (inglés-español): análisis y clasificación". En: CAUCE Revista de Filología y su Didáctica, 20-21, 1997-1998, pp. 593-622.

GreEnbaum, Sidney; QUIRK, Randolph, A Student's Grammar of the English Language. Essex: Longman, 1990.

GreENSTEIN, Ben; WoOD, Diana, "Chapter 2 Chemical Transmission". En: The Endocrine System at a Glance. Hoboken y New Jersey: WileyBlackwell, 2011, pp. 10-12.

Guantiva, Ricardo, "Clasificación de textos especializados a partir de su terminología". En: Íkala, 13.19, 2008, pp. 15-39.

GutiÉRREZ, Bertha, La ciencia empieza en la palabra. Análisis e historia del lenguaje científico. Barcelona: Península, 1998.

—, El lenguaje de las ciencias. Madrid: Gredos, 2005.

HallidAY, M. A. K.; HASAN, Ruqaiya (eds.), "Text and Situation". En: Cohesion in English. Oxford: Routledge, 1976, pp. 19-21.

-, El lenguaje como semiótica social. La interpretación social del lenguaje y del significado. Colombia: Fondo de cultura económica, 1994.

Hatim, Basil; MASON, Ian, Teoría de la traducción: Una aproximación al discurso. Barcelona: Ariel, 1995.

Hurtado AlBiR, Amparo, La enseñanza de la traducción. Castelló: Publicacions de la Universitat Jaume I, 1996.

_, Traducción y traductología. Madrid: Ediciones Cátedra, 2011.

JIMÉNEZ, Isabel, "La sinonimia y la polisemia en la terminología anatómica: términos de ubicación y de relación de estructuras anatómicas". En: Entreculturas, 1, 2009, pp. 579-597.

LÓPEZ, Clara Inés, "Tipologías textuales y géneros en la normalización terminológica y ortotipográfica de la traducción médica". En: Terminologie et traduction, 3, 2000, pp. 95-115. 
LÓPEZ, Juan Gabriel; MINETT, Jacqueline, Manual de Traducción Inglés/Castellano, Teoría y práctica. Barcelona: Gedinsa, 1997.

LORENZO, Emilio, Anglicismos hispánicos. Madrid: Gredos, 1996.

MARTín, Jacinto et al., Los lenguajes especiales. Granada: Colmares, 1996.

MARTín, Gonzalo, Curso de Redacción: teoría y práctica de la composición y del estilo (25. ${ }^{\mathrm{a}}$ ed.). Madrid: Paraninfo, 1995.

MAYOR, M." Blanca, "La importancia de la tipología textual para la formación de traductores médicos". En: Panace@: Revista de Medicina, Lenguaje y Traducción, 8.26, 2007, pp. 124-137.

MONTERO, Sonia, "El artículo y otros fantasmas del nombre". En: redELE, 21, 2011, pp. 1-28.

NAVARRO, Fernando, "La precisión del lenguaje en la redacción médica". Cuadernos de la Fundación Dr. Antonio Esteve, 17, 2009, pp. 89104.

-, "La anglización del español: mucho más allá de bypass, piercing, test, airbag, container y spa". En: Traducción: contacto y contagio. Actas del III Congreso Internacional "El español, lengua de traducción". Bruselas: Electra, 2008.

-, et al., "Uso y abuso de la voz pasiva en el lenguaje médico escrito". En: Medicina Clínica, 103, 1994, pp. 461-464.

NORD, Christiane. "El error en la traducción: categorías y evaluación". En: La enseñanza de la traducción. A. Hurtado (ed.). Castelló de la Plana: Publications de la Universitat Jaume I, 1996. 91-109.

ORdóñeZ, Amalio, Lenguaje médico. Modismos, tópicos y curiosidades. Madrid: Editorial Noesis, 1994.

Rodríguez, Ma Jesús, "Los anglicismos de frecuencia sintácticos en español: estudio empírico". En: RESLA, 15, 2002, pp. 149-170.

SEGURA, Joaquín, "Los anglicismos en el lenguaje médico". En: Panace@: Revista de Medicina, Lenguaje y Traducción, 2.3, 2001, pp. 52-57.

SMITH, Ross, "English in European Spanish". En: English Today, 13, 1997, pp. 22-26.

STUART, Mark, The Complete Guide to Medical Writing. London: Pharmaceutical Press, 2007.

SwALES, John, "The Concept of Genre". En: Genre Analysis: English in Academic and Research Settings. Chapelle, C. y S. Hunston (eds.). Cambridge y New York: Cambridge University Press, 1990, pp. 3367.

UMAÑA, Olga; SuÁREZ, Mercedes, "Descripción y explicación del diseño de instrumentos que miden la competencia traductora y terminológica en traductores profesionales". En: EAN, 70, 2011, pp. 20-41.

VÁZQUEZ, Gerardo, Introducción a la Traductología: curso básico de traducción. Washington DC.: Georgetwon University Press, 1997. 
OTRAS FUENTES DE CONSULTA

Fundéu BBA (Fundación del español urgente). 2016. Disponible en línea en: http://www.fundeu.es/. [Fecha de consulta: 30 de agosto de 2016]. 